\title{
Granulomatosis with Polyangiitis Preceded by Central Diabetes Insipidus
}

\author{
So Sampei, Ryu Watanabe, Tomonori Ishii and Hideo Harigae
}

Key words: central diabetes insipidus, granulomatosis with polyangiitis, hypophysitis

(Intern Med 53: 1725-1726, 2014)

(DOI: 10.2169/internalmedicine.53.2216)

(a)

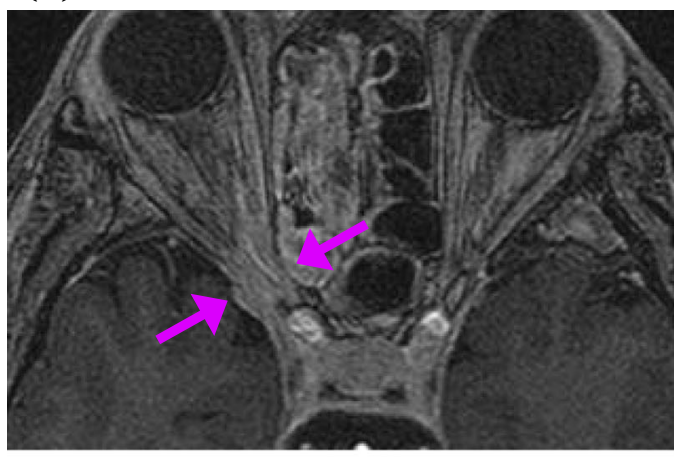

(c)

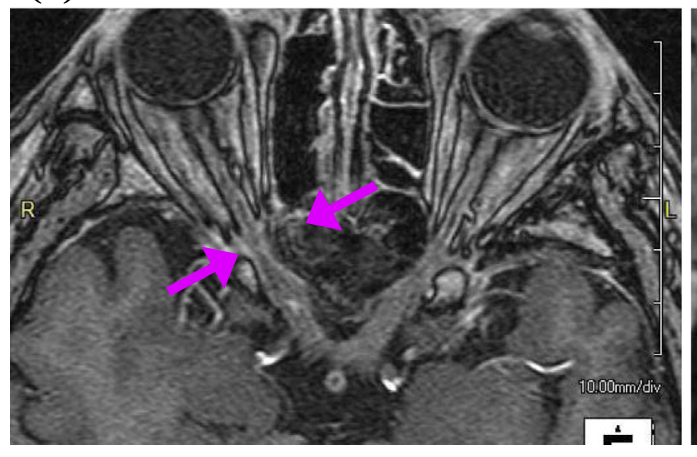

(b)

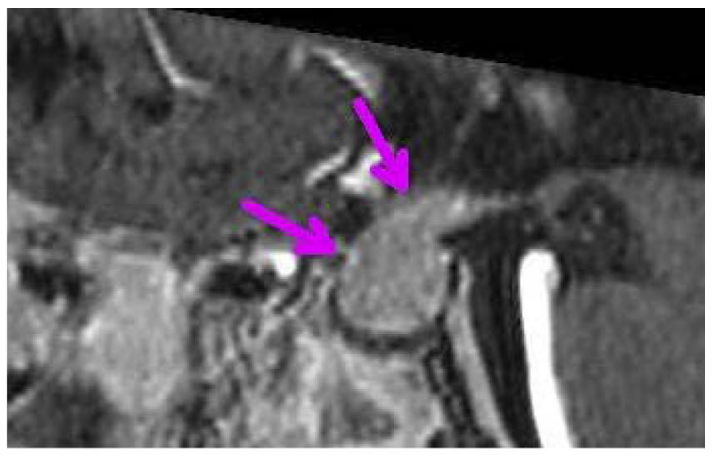

(d)

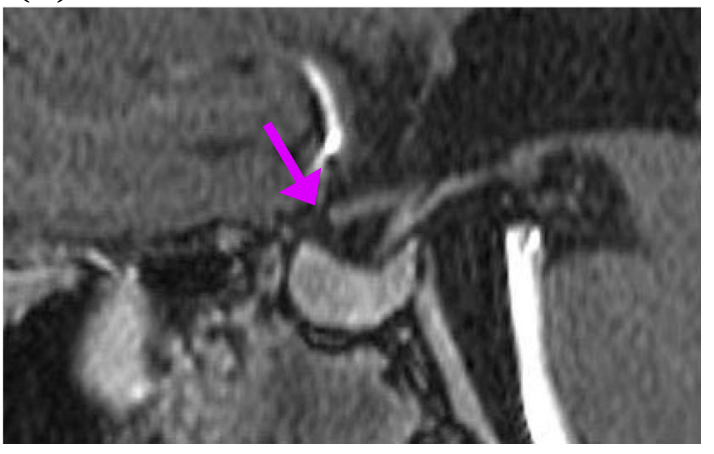

Picture.

A 52-year-old man was admitted to our hospital because of headache and a sudden loss of right-sided vision. He had been diagnosed with central diabetes insipidus (CDI) four months before admission and had been treated with desmopressin. On admission, a magnetic resonance imaging (MRI) scan revealed sphenoidal sinusitis, inflammatory lesions in the right orbital apex, and hypophysitis (Picture a, b). Sphenoidotomy was performed but did not improve his symptoms. The patient's laboratory tests showed elevated Creactive protein level $(1.3 \mathrm{mg} / \mathrm{dL})$ and the presence of myeloperoxidase-anti-neutrophil cytoplasmic antibody (MPO-ANCA, $31.3 \mathrm{U} / \mathrm{mL}$ ). A sphenoid sinus biopsy revealed inflammatory cell infiltration and small-vessel vasculitis. According to Watts' algorithm (1), he was diagnosed with granulomatosis with polyangiitis (GPA) and treated with corticosteroids and intravenous cyclophosphamide therapy. A follow-up MRI scan revealed marked improvement (Picture c, d) and gradual resolution of polyuria, the main symptom of CDI.

There are some case reports regarding pituitary involve- 
ment in GPA patients; however, the majority of them are female and proteinase 3-ANCA-positive (2). To our knowledge, this is the first case report of a male MPO-ANCApositive GPA patient complicated with CDI.

The authors state that they have no Conflict of Interest (COI).

\section{References}

1. Watts R, Lane S, Hanslik T, et al. Development and validation of a consensus methodology for the classification of the ANCAassociated vasculitides and polyarteritis nodosa for epidemiological studies. Ann Rheum Dis 66: 222-227, 2007.

2. Yong TY, Li JY, Amato L, et al. Pituitary involvement in Wegener's granulomatosis. Pituitary 11: 77-84, 2008.

(C) 2014 The Japanese Society of Internal Medicine http://www.naika.or.jp/imonline/index.html 